\title{
Influence of lipid profile and statin administration on arterial stiffness in renal transplant recipients
}

\author{
Zbigniew T. Heleniak ${ }^{1}$, Sarah Illersperger ${ }^{2}$, Susanne Brakemeier ${ }^{2}$, \\ Alicja Dębska-Ślizień ${ }^{1}$, Paul Bach ${ }^{3}$, Klemens Budde ${ }^{2}$, Fabian Halleck ${ }^{2}$ \\ ${ }^{1}$ Department of Nephrology, Transplantology and Internal Medicine, \\ Medical University of Gdansk, Poland \\ ${ }^{2}$ Medizinische Klinik mit Schwerpunkt Nephrologie und Internistische Intensivmedizin, \\ Charité - Universitätsmedizin, Berlin, Germany \\ ${ }^{3}$ Institut für Biometrie und Klinische Epidemiologie, \\ Charité - Universitätsmedizin, Berlin, Germany
}

\begin{abstract}
Background: Hyperlipidemia is one of the major risk factors for developing a cardiovascular disease (CVD) and it is a frequent post-transplant complication, occurring in up to $60 \%$ of the renal transplant recipients (RTRs). Lipid lowering therapy with HMG-CoA reductase inhibitors (statins) is generally recommended and may reduce the overall cardiovascular risk. The aim of this study was to evaluate the lipid profile, statin administration and their relationship with arterial stiffness parameters in RTRs.

Methods: Three hundred and forty-four stable RTRs (62.5\% male) transplanted between 1994 and 2018 were randomly enrolled to the study. The following parameters of arterial stiffness was measured in each patient: ankle brachial index, carotid femoral pulse wave velocity (baPWV left and right, cfPWV) and pulse pressure (PP right and left). The study group was divided based on the use statins: 143 (41.6\%) and 201 (58.4\%). RTRs were qualified to the statin (+) and the statin (-) group, respectively. Results: In the statin (+) as compared to statin (-) group there were more patients with a CVD (32.9\% vs. $14.9 \%$ ) and diabetes (25.2\% vs. $14.4 \%)$. In the whole study group, CVD was associated with a significant increase of both baPWV and cfPWV as well as $P P(8.5 \mathrm{mmHg})$. There were significant differences in arterial stiffness parameters (baPWV, cfPWV, PP) between the statin (+) and the statin (-) group. Conclusions: Arterial stiffness was increased in RTRs with CVD and hyperlipidemia. The control of hyperlipidemia was poor in RTRs. (Cardiol J 2022; 29, 2: 263-271)
\end{abstract}

Key words: arterial stiffness, kidney transplantation, statin, hyperlipidemia

\section{Introduction}

In spite of the improvement in rejection rates long-term survival in renal transplant recipients (RTRs) has remained unchanged and cardiovascular disease (CVDs) are a major cause of death in this patient population [1,2]. Moreover, hyperlipidemia is the major cardiovascular (CV) risk factor and is a frequent post-transplant complication, occurring in up to $60 \%$ of the patients $[1,3,4]$. Lipid lowering therapy statins reduce the $\mathrm{CV}$ risk in patients after kidney transplantation $[5,6]$.

Saran et al. [7] showed that: "the occurrence of CVDs in kidney transplant recipients is affected not only by the traditional risk factors but also by immunosuppressive therapy, earlier dialysis therapy, proteinuria, inflammation or anemia". All these factors lead to increased arterial stiffness [8,9].

Address for correspondence: Dr. Zbigniew T. Heleniak, Department of Nephrology, Transplantology and Internal Medicine, Medical University of Gdansk, ul. Dębinki 7, 80-952 Gdańsk, Poland, tel: +48 502987 604, fax: +48 583452551 , e-mail: zbigniew.heleniak@gumed.edu.pl

Received: 13.12.2019 Accepted: 15.02.2020 Early publication date: 22.04.2020

This article is available in open access under Creative Common Attribution-Non-Commercial-No Derivatives 4.0 International (CC BY-NC-ND 4.0) license, allowing to download articles and share them with others as long as they credit the authors and the publisher, but without permission to change them in any way or use them commercially. 
Carotid-femoral pulse wave velocity (PWV), as an arterial stiffness parameter, is an independent predictor of $\mathrm{CV}$ complications in the general population and high CV patients [10, 11]. Statins treatment mitigates an arterial stiffness, beyond their effects on the lipid profile [10]. Additionally, lipid lowering treatment has pleiotropic effects by enhancing nitric oxide bioavailability, antioxidant effect, and interaction with the renin-angiotensinaldosterone (RAA) system [10, 12]. There are no essential data available concerning the influence of statins on arterial stiffness in RTRs. The main aim of the study was to evaluate the lipid profile, statin administration and their relationship to arterial stiffness parameters in renal transplant recipients.

\section{Methods}

This cross-sectional study enrolled 344 stable RTRs, transplanted between 1994 and 2018, who attended the outpatient unit of the Department of Nephrology Charité - Universitätsmedizin Berlin, Germany, between February and July 2018.

Patients gave their written informed consent. The study was conducted in accordance with the Declaration of Helsinki.

Demographic and clinical information including: renal transplant, CV and diabetic status was analyzed. Additionally, the immunosuppressive protocol, hypertensive and statin treatment were assessed. Data concerning serum creatinine, potassium concentration, hemoglobin, proteinuria, albuminuria and lipids levels refer to a single assessment obtained from medical files of patients.

Furthermore, we investigated the following parameters of arterial stiffness: brachial ankle and carotid femoral pulse wave velocity (baPWV left and right, cfPWV), ankle brachial index (ABI) and also blood pressure $(\mathrm{BP})$, pulse pressure $(\mathrm{PP})$ in each patient using ABI system 100 (Boso Bosch and Sohn, Germany). Additionally, pulsatile stress test (left and right), as a marker of arterial stiffness was assessed using the equation: pulsatile stress test $=$ heart rate $\times$ pulse pressure.

\section{Statistical analyses}

Statistical analyses were performed using the STATSTICA 13.3 PL for Windows software package. Categorical variables are presented as absolute numbers (percentages). Continuous variables are presented as mean value \pm standard deviation (SD) or as median and interquartile range (IQR) for highly skewed variables. Differences in the distribution of continuous variables were assessed using the two-sample t-test or the Mann-Whitney $\mathrm{U}$-test, respectively. The $\chi^{2}$ test was used for the categorical variables. Correlation coefficients were calculated using the Spearman test. Additionally, a simple linear regression model was used to model the relationship between a scalar response (or dependent variable) and one or more explanatory variables (or independent variables). The Shapiro-Wilk test was used to assess normality. In all statistical tests, a p-value $<0.05$ was considered as statistically significant.

\section{Results}

Overall, 344 stable patients were enrolled to the study. The definition of stable patient included: constant level of creatinine and immunosuppressive drugs in the blood and the lack of any CV events during 6 and 12 months before enrolment to the study, respectively.

The study population was divided in two groups based on the statin application. 143 (41.6\%) and $201(58.4 \%)$ were qualified to the group statin $(+)$ and statin (-), respectively. Overall, $86 \%$ of the RTRs under statin treatment received fluvastatin in a mean dose of $44.7 \mathrm{mg} /$ day (55.9\% of the maximal dose). $7 \%$ used pravastatin in a mean dose of $30 \mathrm{mg}$ (75\% of the maximal dose), $4.9 \%$ used atorvastatin in a mean dose of $35.7 \mathrm{mg}$ ( $44.6 \%$ of the maximal dose) and $2.1 \%$ used simvastatin in a mean dose of $23.3 \mathrm{mg}$ ( $58.2 \%$ of maximal dose).

\section{Study population characteristics}

In the group of statins (+) as compared to statin (-) there were more patients with CV $(32.9 \%$ vs. $14.9 \%, \mathrm{p}<0.05)$ and diabetes ( $25.2 \%$ vs. $14.4 \%$, $\mathrm{p}=\mathrm{NS})$. There were more males and the average body mass index (BMI) was higher in the statin $(+)$ group $(\mathrm{p}<0.05)$. The general characteristics of the study participants are summarized in Table 1.

The main causes of end stage renal disease (ESRD) in the study population were glomerulonephritis (the majority were biopsy proven, but the histopathological results weren't available in patient's files), tubulointerstitial nephropathy and polycystic kidney disease. In the statin (+) group the average serum creatinine was higher and estimated glomerular filtration rate (eGFR; CKD-EPI) was significantly lower as compared to the statin $(-)$ group $(\mathrm{p}<0.05)$. The level of albumin in the blood, proteinuria and albuminuria were similar in the statin $(+)$ and $(-)$ groups.

The groups did not differ significantly with respect to the time of renal replacement ther- 
Table 1. Characteristics of the study population.

\begin{tabular}{|c|c|c|c|c|}
\hline & Total study population & Statin $(+)$ & Statin (-) & $\mathbf{P}$ \\
\hline RTRs & 344 & $143(41.6 \%)$ & $201(58.4 \%)$ & $<0.05$ \\
\hline Sex: men & $215(62.5 \%)$ & $94(65.7 \%)$ & $121(60.2 \%)$ & $<0.05$ \\
\hline Age [years] & $52.7 \pm 13.9$ & $56.7 \pm 12.0$ & $49.8 \pm 14.4$ & NS \\
\hline Body mass index $\left[\mathrm{kg} / \mathrm{m}^{2}\right]$ & $25.62 \pm 4.78$ & $29.91 \pm 5.11$ & $24.69 \pm 4.31$ & $<0.05$ \\
\hline Weight $[\mathrm{kg}]$ & $76.16 \pm 17.22$ & $79.83 \pm 17.65$ & $73.53 \pm 16.44$ & $<0.05$ \\
\hline Diabetes mellitus (any type 1, 2, NODAT) & $64(18.6 \%)$ & $36(25.2 \%)$ & $29(14.4 \%)$ & NS \\
\hline Cardiovascular disease (CAD, POAD) & $77(22.4 \%)$ & $47(32.9 \%)$ & $30(14.9 \%)$ & $<0.05$ \\
\hline Hypertension & $298(86.6 \%)$ & $126(88.1 \%)$ & $172(85.5 \%)$ & NS \\
\hline \multicolumn{5}{|l|}{ Reasons of ESRD and KTx: } \\
\hline Primary glomerulonephritis & $186(54.1 \%)$ & $73(55.0 \%)$ & $113(56.2 \%)$ & NS \\
\hline Diabetic nephropathy & $5(1.5 \%)$ & $1(0.7 \%)$ & $4(2 \%)$ & NS \\
\hline Polycystic kidney disease & $56(16.3 \%)$ & $26(18.2 \%)$ & $30(14.9 \%)$ & NS \\
\hline Tubulointerstitial nephritis & $70(20.3 \%)$ & $30(20.9 \%)$ & $40(20 \%)$ & NS \\
\hline Hypertensive nephropathy & $18(5.2 \%)$ & $11(7.7 \%)$ & $7(3.5 \%)$ & NS \\
\hline Unknown etiology & $10(2.9 \%)$ & $2(1.4 \%)$ & $8(4 \%)$ & NS \\
\hline Time of RRT [months] & $58.5(19-97)$ & $48(14-83)$ & $44(6-94)$ & NS \\
\hline Time after KTx [months] & $73(28-140)$ & $88(46-161)$ & $51(12-89)$ & $<0.05$ \\
\hline Preemptive KTx & $46(13.4 \%)$ & $17(11.9 \%)$ & $29(14.4 \%)$ & NS \\
\hline Serum creatinine level [mg/dL] & $1.47(1.19-1.92)$ & $1.56(1.18-2.06)$ & $1.44(1.19-1.85)$ & NS \\
\hline eGFR CKD-EPI [mL/min/1.73 $\left.\mathrm{m}^{2}\right]$ & $50.4 \pm 19.8$ & $47.4 \pm 19.9$ & $52.4 \pm 19.5$ & $<0.05$ \\
\hline Potassium [mmol/L] & $4.3 \pm 0.6$ & $4.3 \pm 0.58$ & $4.3 \pm 0.56$ & NS \\
\hline Hemoglobin [g/dL] & $12.7 \pm 1.7$ & $12.9 \pm 1.8$ & $12.6 \pm 1.7$ & NS \\
\hline Total cholesterol [mg/dL] & $195(164-222)$ & $198(168-222)$ & $191(162-221)$ & NS \\
\hline LDL [mg/dL] & $122(99-146)$ & $120(100-139)$ & $123(98-149)$ & NS \\
\hline $\mathrm{HDL}[\mathrm{mg} / \mathrm{dL}]$ & $51(42-64)$ & $48(39-63)$ & $53(44-66)$ & $<0.05$ \\
\hline Non-HDL [mg/dL] & $138(113-166)$ & $145(119-171)$ & $134(107-165)$ & $<0.05$ \\
\hline Triglycerides [mg/dL] & $155(113-221)$ & $185(128-256)$ & 137 (106-195) & $<0.05$ \\
\hline $\mathrm{LDL}<100 \mathrm{mg} / \mathrm{dL}$ & $93(27 \%)$ & $38(26.6 \%)$ & $55(27.4 \%)$ & NS \\
\hline Non-HDL $<130$ mg/dL & $147(42.7 \%)$ & $54(38.3 \%)$ & $93(46.3 \%)$ & $<0.05$ \\
\hline Triglycerides $<150 \mathrm{mg} / \mathrm{dL}$ & $168(48.8 \%)$ & $52(36.4 \%)$ & $116(57.7 \%)$ & $<0.05$ \\
\hline Albumin $[\mathrm{g} / \mathrm{L}]$ & $43.46 \pm 3.28$ & $43.59 \pm 3.12$ & $43.64 \pm 3.09$ & NS \\
\hline Albuminuria [mg/day] & $41.5(9.3-145)$ & $31(8-176)$ & $45(11-145)$ & NS \\
\hline Proteinuria [mg/day] & $171(114-380)$ & $172(108-365)$ & $170(120-385)$ & NS \\
\hline Albuminuria $[\mathrm{mg} / \mathrm{g}]$ creatinine & $49(15-156)$ & $60(15-203)$ & $48(15-136)$ & NS \\
\hline Proteinuria $[\mathrm{mg} / \mathrm{g}]$ creatinine & $138(84-322)$ & $137(88-357)$ & $138(82-321)$ & NS \\
\hline Cyclosporine & $73(21.2 \%)$ & $39(27.3 \%)$ & $34(16.9 \%)$ & $<0.05$ \\
\hline Tacrolimus & $212(61.6 \%)$ & $69(48.2 \%)$ & $143(71.1 \%)$ & $<0.05$ \\
\hline Steroids & $176(51.2 \%)$ & $68(47.5 \%)$ & $108(53.4 \%)$ & NS \\
\hline Mycophenolate mofetil & $150(43.6 \%)$ & $78(36.4 \%)$ & $98(48.7 \%)$ & $<0.05$ \\
\hline Mycophenolate sodium & $171(49.7 \%)$ & $107(54.5 \%)$ & $93(46.3 \%)$ & NS \\
\hline Azathioprin & $5(1.5 \%)$ & $4(2.8 \%)$ & $1(0.5 \%)$ & NS \\
\hline mTOR & $10(2.9 \%)$ & $6(4.2 \%)$ & $4(2 \%)$ & NS \\
\hline Belatacept & $41(11.9 \%)$ & $25(17.5 \%)$ & $16(8 \%)$ & $<0.05$ \\
\hline RAA system blockade & $204(59.3 \%)$ & $94(65.7 \%)$ & $110(54.7 \%)$ & $<0.05$ \\
\hline Calcium channel blockers & $158(45.9 \%)$ & $71(49.6 \%)$ & $87(43.3 \%)$ & NS \\
\hline Beta-blockers & $241(70.1 \%)$ & $119(83.2 \%)$ & $124(61.7 \%)$ & $<0.05$ \\
\hline Diuretics & $120(34.9 \%)$ & $72(50.3 \%)$ & $48(23.9 \%)$ & $<0.05$ \\
\hline Erythropoietin stimulating agent & $47(13.7 \%)$ & $31(21.7 \%)$ & $36(17.9 \%)$ & NS \\
\hline
\end{tabular}

Data are show as mean \pm standard deviation or number (percentage) or median (interquartile range). CAD — coronary artery disease; eGFR - estimated glomerular filtration rate; ESRD - end stage renal disease; HDL - high density lipoprotein KTx - kidney transplantation; LDL - low density lipoprotein; mTOR — mammalian target of rapamycin; NODAT — new onset diabetes after transplantation; NS — not statistically significant; POAD - peripheral obliterans artery disease; RAA — renin-angiotensin-aldosterone; RRT — renal replacement therapy; RTRs - renal transplant recipients 
Table 2. Arterial stiffness parameters and blood pressure in the study population.

\begin{tabular}{lcccc}
\hline & Total study population & Statin $(+)$ & Statin $(-)$ & $P$ \\
\hline baPWV right [m/s] & $11.8(10.7-13.3)$ & $12.0(10.0-13.7)$ & $11.7(10.6-12.9)$ & $<0.05$ \\
baPWV left [m/s] & $12.0(10.9-13.5)$ & $12.3(11.2-14.4)$ & $11.7(10.6-13.0)$ & $<0.05$ \\
cfPWV [m/s] & $7.9(6.9-9.5)$ & $8.1(7-9.8)$ & $7.7(6.7-9.2)$ & $<0.05$ \\
SBP right arm [mmHg] & $140.7 \pm 17.7$ & $143.8 \pm 18.2$ & $138.5 \pm 17$ & $<0.05$ \\
SBP left arm $[\mathrm{mmHg}]$ & $139.6 \pm 20.1$ & $142.7 \pm 20.4$ & $137.4 \pm 19.7$ & $<0.05$ \\
DBP right arm [mmHg] & $85.8 \pm 10.3$ & $86.5 \pm 10.0$ & $85.4 \pm 10.4$ & $\mathrm{NS}$ \\
DBP left arm $[\mathrm{mmHg}]$ & $85.7 \pm 10.9$ & $86.2 \pm 10.2$ & $85.2 \pm 10.9$ & $\mathrm{NS}$ \\
PP right arm [mmHg] & $54.6 \pm 14.7$ & $56.8 \pm 15.0$ & $53.1 \pm 14.3$ & $<0.05$ \\
PP left arm [mmHg] & $54.0 \pm 15.9$ & $56.5 \pm 15.7$ & $52.1 \pm 15.9$ & $<0.05$ \\
Pulsatile stress right & $3521 \pm 1012$ & $3599 \pm 994$ & $3469 \pm 1024$ & $<0.05$ \\
Pulsatile stress left & $3520 \pm 1225$ & $3611 \pm 1258$ & $3454 \pm 1202$ & $<0.05$ \\
ABI right & $1.08 \pm 0.17$ & $1.08 \pm 0.23$ & $1.09 \pm 0.10$ & $\mathrm{NS}$ \\
ABI left & $1.09 \pm 0.13$ & $1.07 \pm 0.16$ & $1.10 \pm 0.11$ & $\mathrm{NS}$ \\
\hline
\end{tabular}

Data are show as mean \pm standard deviation or median (interquartile range). $\mathrm{ABI}$ — ankle brachial index; baPWV — brachial ankle pulse wave velocity; cfPWV — carotid femoral pulse wave velocity; DBP — diastolic blood pressure; NS — not statistically significant; PP — pulse pressure; SBP — systolic blood pressure

apy before transplantation, but the time after transplantation was longer (88 vs. 51 months, $\mathrm{p}<0.05)$ in the statin $(+)$ group.

\section{Immunosuppressive regimen in the study population}

Calcineurin inhibitors were used in $82.8 \%$ of the study population. Cyclosporine was administered in $27.3 \%$ vs. $16.9 \%(\mathrm{p}<0.05)$ and tacrolimus in $48.2 \%$ vs. $71.1 \%(\mathrm{p}<0.05)$ of the patients in the statin $(+)$ and (-) group, respectively. $36.4 \%$ vs. $48.7 \%$ of the participants used mycophenolate mofetil (MMF) in the statin $(+)$ and (-) group, respectively. No significant differences were observed in terms of MMF/ /mycophenolate sodium (MPS), azathioprin and mammalian target of rapamycin (mTOR) agents between both groups. In the statin $(+)$ cohort more patients received belatacept $17.5 \%$ vs. $8 \%$ ( $p<0.05)$. In $59.3 \%$ of the participants RAA blockers were implemented. In the statin (+) and (-) group $65.7 \%$ vs. $54.7 \%$ of the patients received RAA blockers $(\mathrm{p}<0.05)$. Betablockers and diuretics were prescribed more often in the statin $(+)$ group $(\mathrm{p}<0.05)$.

\section{The control and treatment of hypertension}

The control of systolic BP (SBP) and diastolic $\mathrm{BP}(\mathrm{DBP})$ was significantly worse in the statin $(+)$ group $(\mathrm{p}<0.05)$. Moreover, $\mathrm{PP}$ value was higher in statin $(+)$ patients (Table 2). In group with lipid parameters as: low density lipoprotein (LDL) $\geq 100 \mathrm{mg} / \mathrm{dL}$ and non-high density lipoprotein (non-HDL) $\geq 130 \mathrm{mg} / \mathrm{dL}$; SBP (p < 0.05), DBP
$(\mathrm{p}=\mathrm{NS})$ and PP $(\mathrm{p}<0.05)$ were higher as compare to group with $\mathrm{LDL}<100 \mathrm{mg} / \mathrm{dL}$ and non-HDL $<130 \mathrm{mg} / \mathrm{dL}$, respectively. The differences in SBP, DBP and PP value did not differ significantly between patients with the level of triglycerides $\geq 150$ $\mathrm{mg} / \mathrm{dL}$ and $<150 \mathrm{mg} / \mathrm{dL}$. The statin (+) participants used significantly more RAA blockers, beta-blockers and diuretics $(\mathrm{p}<0.05)$. No difference in terms of calcium channel blockers administration were noticed.

\section{Lipid parameters in study group}

The level of non-HDL and triglycerides was higher $(\mathrm{p}<0.05)$ in the statin $(+)$ group. No differences in total and LDL cholesterol (LDL-C) levels between statin $(+)$ and statin $(-)$ were observed. The values of HDL-cholesterol (HDL-C) differed significantly in statin $(+)$ and statin $(-)$ groups (48 vs. $53 \mathrm{mg} / \mathrm{dL} ; \mathrm{p}<0.05$ ).

The aim of treatment of hyperlipidemia (LDL $<100 \mathrm{mg} / \mathrm{dL}$ ) was achieved in $26.6 \%$ vs. $27.4 \%$ $(\mathrm{p}=\mathrm{NS})$ in statin $(+)$ and statin (-) groups, respectively. In $38.3 \%$ vs. $46.3 \%$ of patients $(\mathrm{p}<0.05)$ in statin (+) and statin (-) groups, non-HDL $<130$ $\mathrm{mg} / \mathrm{dL}$ was observed.

\section{Arterial stiffness in study group}

The values of arterial stiffness parameters (baPWV, cfPWV, PP, pulsatile stress test) and SBP were higher $(\mathrm{p}<0.05)$ in the statin $(+)$ as compared to the statin (-) group. There were no differences in terms of DBP and ABI between both groups (Table 2). 
Table 3. Arterial stiffness parameters and blood pressure in groups with different level of lowdensity lipoprotein (LDL) cholesterol.

\begin{tabular}{|c|c|c|c|}
\hline & $\mathrm{LDL} \geq 100 \mathrm{mg} / \mathrm{dL}$ & $\mathrm{LDL}<100 \mathrm{mg} / \mathrm{dL}$ & $\mathbf{P}$ \\
\hline Renal transplant recipients & 251 & 93 & $<0.05$ \\
\hline SBP right arm [mmHg] & $141.9 \pm 17.3$ & $137.1 \pm 18.2$ & $<0.05$ \\
\hline SBP left arm [mmHg] & $141.9 \pm 15.3$ & $133.6 \pm 19.7$ & $<0.05$ \\
\hline DBP right arm [mmHg] & $86.1 \pm 10.6$ & $85.2 \pm 9.1$ & NS \\
\hline DBP left arm [mmHg] & $86.8 \pm 10.2$ & $82.5 \pm 12.4$ & $<0.05$ \\
\hline Pulse pressure right & $55.8 \pm 15.3$ & $51.2 \pm 12.4$ & $<0.05$ \\
\hline Pulse pressure left & $55.1 \pm 16.3$ & $51.1 \pm 14.3$ & 0.07 \\
\hline $\mathrm{ABI}$ right & $1.08 \pm 0.17$ & $1.10 \pm 0.18$ & NS \\
\hline ABI left & $1.08 \pm 0.11$ & $1.11 \pm 0.17$ & NS \\
\hline Pulsatile stress right & $3603 \pm 1054$ & $3291 \pm 853$ & $<0.05$ \\
\hline Pulsatile stress left & $3324 \pm 1274$ & $3256 \pm 1050$ & $<0.05$ \\
\hline baPWV right $[\mathrm{m} / \mathrm{s}]$ & $11.8(10.8-13.5)$ & $11.6(10.6-13.3)$ & NS \\
\hline baPWV left [m/s] & $12.0(10.9-13.8)$ & $11.8(10.7-13.1)$ & NS \\
\hline $\operatorname{cfPWV}[\mathrm{m} / \mathrm{s}]$ & $8.0(7-9.5)$ & $7.5(6.6-8.7)$ & $<0.05$ \\
\hline
\end{tabular}

Data are show as mean \pm standard deviation or median (interquartile range). Coversion factor for SI unit is as follows: for LDL divide by 38.67 . $\mathrm{ABI}$ — ankle brachial index; baPWV — brachial ankle pulse wave velocity; cfPWV — carotid femoral pulse wave velocity; DBP — diastolic blood pressure; NS — not statistically significant; PP — pulse pressure; SBP — systolic blood pressure

\section{Lipids, blood pressure and arterial stiffness parameters}

Patients with LDL-C level $<100 \mathrm{mg} / \mathrm{dL}$, had better control of SBP and DBP $(\mathrm{p}<0.05)$ as compared to LDL-C $\geq 100 \mathrm{mg} / \mathrm{dL}$. There were significantly lower values of arterial stiffness parameters (PP, pulsatile stress test and cfPWV) in the group with $\mathrm{LDL}<100 \mathrm{mg} / \mathrm{dL}(\mathrm{p}<0.05)$. No differences were observed for ABI and baPWV (Table 3). In the group with non-HDL-C $\geq 130 \mathrm{mg} / \mathrm{dL}$ SBP and DBP were higher. Moreover, PP right and left were 56.3 vs. $52.2 \mathrm{mmHg}(\mathrm{p}=0.07)$ and 56.1 vs. 51.2 $\mathrm{mmHg}(\mathrm{p}<0.05)$ in the group with non-HDL-C $\geq 130 \mathrm{mg} / \mathrm{dL}$ and $<130 \mathrm{mg} / \mathrm{dL}$, respectively. The arterial stiffness parameters ABI, pulsatile stress test, baPWV and cfPWV did not differ between both groups (Table 4). There were no significant differences in SBP and DBP between patients with triglycerides $\geq 150 \mathrm{mg} / \mathrm{dL}$ and $<150 \mathrm{mg} / \mathrm{dL}$. The values of baPWV left and cfPWV were significantly lower in patients with triglycerides $<150 \mathrm{mg} / \mathrm{dL}$. ABI, PP, pulsatile stress test and baPWV left did not differ between both groups (Table 5).

\section{Relationship between treatment with statins and arterial stiffness parameters}

In the statin (+) group the mean value of PP right, PP left and baPWV left was higher by $1.83 \mathrm{mmHg}, 2.18 \mathrm{mmHg}$ and $0.34 \mathrm{~m} / \mathrm{s}$ as compared to the statin (-) group, respectively.
The level of $\mathrm{LDL} \geq 100 \mathrm{mg} / \mathrm{dL}$ was associated with a significant increase of PP right $(2.33 \mathrm{mmHg})$ and PP left $(2.1 \mathrm{mmHg})$ as compared to patients with $\mathrm{LDL}<100 \mathrm{mg} / \mathrm{dL}$. In patients with $\mathrm{LDL}$ $\geq 100 \mathrm{mg} / \mathrm{dL}$, the pulsatile stress right and left was higher by 156 and 181 relative to the group with $\mathrm{LDL}<100 \mathrm{mg} / \mathrm{dL}$, respectively. The relationship between the treatment with statins and arterial stiffness parameters is presented in Tables 3,4 and 5 . It is worth to underline, that arterial stiffness was higher in the statin (+) group.

\section{Multivariate analysis}

Adjusted for age, sex, diabetes and CV status, the pulse pressure right/left measured in both groups, the value was higher in the statin $(+)$ group, but the difference was not statistically significant. Similar results were attained for participants with non-HDL $\geq 130 \mathrm{mg} / \mathrm{dL}$ vs. $<130 \mathrm{mg} / \mathrm{dL}$ and $\mathrm{LDL} \geq 100 \mathrm{mg} / \mathrm{dL}$ vs. $<100 \mathrm{mg} / \mathrm{dL}$.

\section{Discussion}

Statin treatment, lipids level and cardioand renal protection in RTRs

A protective effect of statin treatment on cardiac endpoints has consistently been confirmed in different populations [13]. Statins protect nephrological patients from $\mathrm{CV}$ complications, but the effect is lower in groups with severe renal failure 
Table 4. Arterial stiffness parameters and blood pressure in groups with different level of non-high density lipoprotein (HDL) cholesterol.

\begin{tabular}{lccc}
\hline & Non-HDL $\geq \mathbf{1 3 0} \mathbf{~} \mathbf{g} / \mathbf{d L}$ & Non-HDL $<\mathbf{1 3 0} \mathbf{~ g} / \mathbf{d L}$ & $\mathbf{P}$ \\
\hline Renal transplant recipients & 195 & 149 & $\mathrm{NS}$ \\
SBP right arm [mmHg] & $142.4 \pm 17.3$ & $138.1 \pm 17.8$ & $<0.05$ \\
SBP left arm [mmHg] & $143.1 \pm 19.1$ & $134.7 \pm 19.2$ & $\mathrm{NS}$ \\
DBP right arm [mmHg] & $86.0 \pm 10.0$ & $85.4 \pm 10.6$ & $<0.05$ \\
DBP left arm [mmHg] & $87.1 \pm 10.4$ & $83.5 \pm 11$ & 0.07 \\
Pulse pressure right & $56.3 \pm 15.4$ & $52.2 \pm 12.9$ & $<0.05$ \\
Pulse pressure left & $56.1 \pm 16.3$ & $51.2 \pm 14.9$ & $\mathrm{NS}$ \\
ABI right & $1.07 \pm 0.11$ & $1.10 \pm 0.23$ & $\mathrm{NS}$ \\
ABI left & $1.08 \pm 0.12$ & $1.10 \pm 0.14$ & $\mathrm{NS}$ \\
Pulsatile stress right & $3626 \pm 1119$ & $3382 \pm 843$ & $\mathrm{NS}$ \\
Pulsatile stress left & $3650 \pm 1332$ & $3344 \pm 1058$ & $\mathrm{NS}$ \\
baPWV right [m/s] & $12.0(11.0-13.3)$ & $11.7(10.5-13.3)$ & $\mathrm{NS}$ \\
baPWV left [m/s] & $12.0(10.9-13.5)$ & $11.9(10.6-13.8)$ & $\mathrm{NS}$ \\
cfPWV [m/s] & $8.0(7.2-9.4)$ & $7.6(6.6-9.5)$ & \\
\hline
\end{tabular}

Data are show as mean \pm standard deviation or median (interquartile range). Coversion factor for SI unit is as follows: for HDL divide by 38.67. ABI — ankle brachial index; baPWV — brachial ankle pulse wave velocity; cfPWV — carotid femoral pulse wave velocity;

DBP - diastolic blood pressure; NS - not statistically significant; PP - pulse pressure; SBP - systolic blood pressure

Table 5. Arterial stiffness parameters and blood pressure in groups with different level of triglicerydes.

\begin{tabular}{lccc}
\hline & Triglicerydes $\geq \mathbf{1 5 0} \mathbf{~} \mathbf{g} / \mathbf{d L}$ & Triglicerydes $<\mathbf{1 5 0} \mathbf{~} \mathbf{g} / \mathbf{d L}$ & $\mathbf{P}$ \\
\hline Renal transplant recipients & 175 & 169 & $\mathrm{NS}$ \\
SBP right arm [mmHg] & $141.5 \pm 17.3$ & $139.6 \pm 17.9$ & $\mathrm{NS}$ \\
SBP left arm [mmHg] & $140.4 \pm 18.4$ & $138.5 \pm 21.5$ & $\mathrm{NS}$ \\
DBP right arm [mmHg] & $86.6 \pm 10.0$ & $85.9 \pm 10.5$ & $\mathrm{NS}$ \\
DBP left arm [mmHg] & $86.3 \pm 10.1$ & $84.8 \pm 11.4$ & $\mathrm{NS}$ \\
Pulse pressure right & $55.8 \pm 15.3$ & $53.2 \pm 13.9$ & $\mathrm{NS}$ \\
Pulse pressure left & $54.2 \pm 15,1$ & $53.6 \pm 16.8$ & $\mathrm{NS}$ \\
ABI right & $1.08 \pm 0.10$ & $1.09 \pm 0.22$ & $\mathrm{NS}$ \\
ABI left & $1.08 \pm 0.10$ & $1.10 \pm 0.15$ & $\mathrm{NS}$ \\
Pulsatile stress right & $3578 \pm 1056$ & $3382 \pm 843$ & $\mathrm{NS}$ \\
Pulsatile stress left & $3511 \pm 1164$ & $3344 \pm 1058$ & $\mathrm{NS}$ \\
baPWV right [m/s] & $11.8(11.0-13.7)$ & $11.7(10.5-12.9)$ & $\mathrm{NS}$ \\
baPWV left [m/s] & $12.3(11.2-13.8)$ & $11.6(10.6-13.2)$ & $<0.05$ \\
cfPWV [m/s] & $8.0(7.0-9.8)$ & $7.6(6.7-9.1)$ & $<0.05$ \\
\hline
\end{tabular}

Data are show as mean \pm standard deviation or median (interquartile range). Coversion factor for SI unit is as follows: for triglycerides divide by 88.7. ABI - ankle brachial index; baPWV — brachial ankle pulse wave velocity; cfPWV — carotid femoral pulse wave velocity; DBP — diastolic blood pressure; NS — not statistically significant; PP — pulse pressure; SBP — systolic blood pressure

[14]. However, although cardio- and reno-protective effects of statins have been well documented in the general population, the effects have been less studied in RTRs. Moreover, only $36 \%$ of RTRs are treated with statins according to Clinical Practice Guidelines for Managing Dyslipidemias in Kidney Transplant Patients [15]. The results of the Assessment of Lescol in Renal Transplantation (ALERT) study, showed that fluvastatin $(40 \mathrm{mg} /$ /day) decreased the level of LDL-C by $32 \%$. On the other hand, the primary endpoint composed of cardiac death, nonfatal myocardial infarction or coronary intervention procedure, was reduced by $17 \%$, but this difference was not statistically sig- 
nificant [14]. Moreover, the outcomes revealed that only $41.6 \%$ of participants used statins [14]. The present study showed that treatment with statins was insufficient, because only $26.6 \%$ of the RTRs achieved the main aim of hypolipidemic treatment ( $\mathrm{LDL}<100 \mathrm{mg} / \mathrm{dL}$ ). It should be underlined, that on average, patients received between $44.6 \%$ and $75 \%$ of the maximal dose of statins (atorvastatin, fluvastatin, simvastatin, pravastatin).

Statins are known to have pleiotropic effects such as anti-inflammatory, antiproliferative, and immunosuppressive effects, which suggested their possible impact on acute allograft rejection [16]. Regarding vascular remodeling, interstitial fibrosis, and tubular atrophy (IF-TA) intensive statin treatment may halt the progression of IF-TA protecting it from atherosclerosis [17, 18]. The beneficial effects of statins on coronary atherosclerosis progression have been attributed not only to lipid-lowering effects, but probably also to their anti-inflammatory properties. Furthermore, nephroprotective aspects of statins have been ascribed to regulate fibrogenic mechanisms and their effect on endothelial dysfunction [19]. Cochrane meta-analysis showed in 22 studies, that statins may reduce the relative risk of $\mathrm{CV}$ events in RTRs [20].

\section{Relationship between lipids, blood pressure and arterial stiffness parameters}

Pulse wave velocity and $\mathrm{PP}$ are a non-invasive method to assess a central arterial stiffness that predicts independently CVD morbidity and mortality [21]. Increased PWV serves as target organ damage in subjects with hypertension and is included in risk stratification for CVD events [21].

Moreover, Korogiannou et al. [22] provide an overview of the field of arterial stiffness in renal transplantation and the prognostic significance of arterial stiffness for CV events, renal events and mortality in these individuals, as well as studies examining the changes in arterial stiffness following renal transplantation. PWV is considered as the 'gold standard' method for the assessment of arterial stiffness [21]. Increased aortic stiffness leads to a premature return in heart's late systole and increases central PP and SBP. It resulted in left ventricular hypertrophy, a well-established risk factor for coronary events [21]. In addition, PP, as the difference between SBP and DBP, is a major $\mathrm{CV}$ risk factor directly related to CV events [23].

In the current study values of arterial stiffness parameters (baPWV, cfPWV, PP, pulsatile stress test) and SBP were higher $(\mathrm{p}<0.05)$ in the statin
$(+)$ as compared to the statin (-) group. It is worth mentioning that in the statin (+) group, there were more patients with diabetes, CVD and hypertension. Additionally, it is prudent to underline, that current patients with a lower level of LDL $(<100$ $\mathrm{mg} / \mathrm{dL})$ and non-HDL $(<130 \mathrm{mg} / \mathrm{dL})$, better values of BP and arterial stiffness parameters were observed.

Theilade et al. [24] failed to show an independent relationship between brachial PP and CV events in a high-risk population with diabetes, $\mathrm{CKD}$ and anemia. In transplant patients, increased stiffness of the common carotid artery predicts the occurrence of CV events [25]. More recently, in RTRs, PWV was associated with the combined end point of doubling plasma creatinine and $\mathrm{CV}$ events [25].

Additionally, D'elia et al. [10] indicated: “a direct association between statin use and decreased arterial stiffness in the controlled randomized intervention trial of statin use having PWV changes as the main endpoint in the general population, patients with chronic kidney disease, hypercholesterolemia, cardiovascular disease and obturative sleep apnea”.

Navarro-Muñoz et al. [26] showed the improvement of LDL profile after atorvastatin treatment in patients after kidney transplantation with worse PWV ( $>9.75 \mathrm{~m} / \mathrm{s})$, transforming growth factor-beta 1 levels were significantly reduced after 3 months of treatment.

\section{Limitations of the study}

There are several limitations of this study that should be considered when interpreting the results. First, the present results do not prove direct decreasing of arterial stiffness by statins. Additionally, the duration of statin therapy, indications and adherence for this treatment were not assessed. Nevertheless, it can be considered that more intensive statin treatment in RTRs could mitigate aortic stiffness. Second, in spite of the fact that the study population was divided in statin (+) and statin (-), it was a heterogenous group, with different comorbidity conditions and dissimilar time of dialysis and the period after renal transplantation. Third, there are the limitations of using high doses of statins in renal transplant recipients due to interaction with calcineurin inhibitor and impaired graft function.

Fourth, the use of office blood pressure readings, done once, to monitor the quality of BP control may be subject to significant error due to white-coat syndrome. In reality therefore, treatment results may even be better. In addition, the assessment of antihypertensive treatment was 
based on medical records. Hence, there might be small differences between these data and real-life data.

However, despite these limitations, the study highlights some important information for the RTRs. In this matter, longer observation time are needed as well as repeated measurements of all arterial stiffness parameters.

\section{Conclusions}

In summary the studied population had intended to show that the administration of statin was low. Additionally, hyperlipidemia was poorly controlled. On the other hand, arterial stiffness was lower in patients with better control of hyperlipidemia. Therefore, there is a necessity for more frequent lipid-lowering therapy implementation. It may contribute to the reduction of arterial stiffness and can result in the reduction of CV risk of RTRs.

\section{Conflict of interest: None declared}

\section{References}

1. Robertsen I, Asberg A, Granseth T, et al. More potent lipid-lowering effect by rosuvastatin compared with fluvastatin in everolimus-treated renal transplant recipients. Transplantation. 2014; 97(12): 1266-1271, doi: 10.1097/01.TP.0000443225.66960.7e, indexed in Pubmed: 24521776.

2. Mason J, Kleemann F, Bankart J, et al. Blood pressure in renal transplant recipients: are there independent predictors for achieving target blood pressure? Nephron Clin Pract. 2009; 111(3): c159-c166, doi: 10.1159/000198236, indexed in Pubmed: 19182491.

3. Hjelmesaeth J, Hartmann A, Midtvedt K, et al. Metabolic cardiovascular syndrome after renal transplantation. Nephrol Dial Transplant. 2001; 16(5): 1047-1052, doi: 10.1093/ndt/16.5.1047, indexed in Pubmed: 11328915.

4. Pannu HS, Singh D, Sandhu JS. Lipid profile before and after renal transplantation. A longitudinal study. Ren Fail. 2003; 25(3): 411-417, doi: 10.1081/jdi-120021153, indexed in Pubmed: 12803504.

5. Jardine AG, Gaston RS, Fellstrom BC, et al. Prevention of cardiovascular disease in adult recipients of kidney transplants. Lancet. 2011;378(9800):1419-1427, doi:10.1016/S0140-6736(11)61334-2, indexed in Pubmed: 22000138.

6. Stevens PE, Levin A. Evaluation and management of chronic kidney disease: synopsis of the kidney disease: improving global outcomes 2012 clinical practice guideline. Ann Intern Med. 2013; 158(11): 825-830, doi: 10.7326/0003-4819-158-11-20130604000007, indexed in Pubmed: 23732715.

7. Saran M, Czyżewski Ł, Wyzgał J, et al. Comparative analysis of arterial stiffness and body composition in early and late periods after kidney transplantation. Transplant Proc. 2018; 50(6): 1829-1833, doi: 10.1016/j.transproceed.2018.03.110, indexed in Pubmed: 30056909.
8. Boutouyrie P, Fliser D, Goldsmith D, et al. Assessment of arterial stiffness for clinical and epidemiological studies: methodological considerations for validation and entry into the European Renal and Cardiovascular Medicine registry. Nephrol Dial Transplant. 2014; 29(2): 232-239, doi: 10.1093/ndt/gft309, indexed in Pubmed: 24084326.

9. Holdaas H, de Fijter JW, Cruzado JM, et al. ELEVATE Study Group. Cardiovascular parameters to 2 years after kidney transplantation following early switch to everolimus without calcineurin inhibitor therapy: an analysis of the randomized ELEVATE study. Transplantation. 2017; 101(10): 2612-2620, doi: 10.1097/ TP.0000000000001739, indexed in Pubmed: 28333860.

10. D'elia L, La Fata E, Iannuzzi A, et al. Effect of statin therapy on pulse wave velocity: A meta-analysis of randomized controlled trials. Clin Exp Hypertens. 2018; 40(7): 601-608, doi: 10.1080/10641963.2017.1411498, indexed in Pubmed: 29420075.

11. Laurent S, Cockcroft J, Van Bortel L, et al. European Network for Non-invasive Investigation of Large Arteries. Expert consensus document on arterial stiffness: methodological issues and clinical applications. Eur Heart J. 2006; 27(21): 2588-2605, doi: 10.1093/ eurheartj/eh1254, indexed in Pubmed: 17000623.

12. Zhou MS, Jaimes EA, Raij L. Atorvastatin prevents end-organ injury in salt-sensitive hypertension: role of eNOS and oxidant stress. Hypertension. 2004; 44(2): 186-190, doi: 10.1161/01. HYP.0000136395.06810.cf, indexed in Pubmed: 15238570.

13. Holdaas H, Holme I, Schmieder RE, et al. Rosuvastatin in diabetic hemodialysis patients. J Am Soc Nephrol. 2011; 22(7): 1335-1341, doi: 10.1681/ASN.2010090987, indexed in Pubmed: 21566054.

14. Waters DD. LDL-cholesterol lowering and renal outcomes. Curr Opin Lipidol. 2015; 26(3): 195-199, doi: 10.1097/ MOL.0000000000000176, indexed in Pubmed: 25887677.

15. Kasiske BL. Clinical practice guidelines for managing dyslipidemias in kidney transplant patients. Am J Transplant. 2005; 5(6): 1576, doi: 10.1111/j.1600-6143.2005.00827.x, indexed in Pubmed: 15888073.

16. Kasiske BL, Heim-Duthoy KL, Singer GG, et al. The effects of lipid-lowering agents on acute renal allograft rejection. Transplantation. 2001; 72(2): 223-227, doi: 10.1097/00007890200107270-00009, indexed in Pubmed: 11477342.

17. Palmer SC, Navaneethan SD, Craig JC, et al. HMG CoA reductase inhibitors (statins) for kidney transplant recipients. Cochrane Database Syst Rev. 2014(1): CD005019, doi: 10.1002/14651858. CD005019.pub4, indexed in Pubmed: 24470059.

18. Tuncer M, Süleymanlar G, Ersoy FF, et al. Comparison of the effects of simvastatin and pravastatin on acute rejection episodes in renal transplant patients. Transplant Proc. 2000; 32(3): 622-625, doi: 10.1016/s0041-1345(00)00921-0, indexed in Pubmed: 10812143.

19. Cravedi P, Perico N, Remuzzi G. Non-immune interventions to protect kidney allografts in the long term. Kidney Int Suppl. 2010(119): S71-S75, doi: 10.1038/ki.2010.427, indexed in Pubmed: 21116322.

20. Cosio FG, Pesavento TE, Pelletier RP, et al. Patient survival after renal transplantation III: the effects of statins. Am J Kidney Dis. 2002; 40(3): 638-643, doi: 10.1053/ajkd.2002.34927, indexed in Pubmed: 12200817.

21. Grigoropoulou P, Tentolouris A, Eleftheriadou I, et al. Effect of 12-month intervention with low-dose atorvastatin on pulse wave velocity in subjects with type 2 diabetes and 
dyslipidaemia. Diab Vasc Dis Res. 2019; 16(1): 38-46, doi: 10.1177/1479164118805320, indexed in Pubmed: 30328360.

22. Korogiannou M, Xagas E, Marinaki S, et al. Arterial stiffness in patients with renal transplantation; associations with co-morbid conditions, evolution, and prognostic importance for cardiovascular and renal outcomes. Front Cardiovasc Med. 2019; 6: 67, doi: 10.3389/fcvm.2019.00067, indexed in Pubmed: 31179288.

23. O'Rourke M, O'Brien C, Weber T. Arterial Stiffness, Wave Reflection, Wave Amplification: Basic Concepts, Principles of Measurement and Analysis in Humans. Blood Pressure and Arterial Wall Mechanics in Cardiovascular Diseases. 2014: 3-13, doi: 10.1007/978-1-4471-5198-2_1.

24. Theilade S, Claggett B, Hansen TW, et al. TREAT investigators. Pulse pressure is not an independent predictor of outcome in type 2 diabetes patients with chronic kidney disease and anemia - the Trial to Reduce Cardiovascular Events with Aranesp Therapy (TREAT). J Hum Hypertens. 2016; 30(1): 46-52, doi: 10.1038/jhh.2015.22, indexed in Pubmed: 25810068.

25. Delahousse M, Chaignon M, Mesnard L, et al. Aortic stiffness of kidney transplant recipients correlates with donor age. J Am Soc Nephrol. 2008; 19(4): 798-805, doi: 10.1681/ASN.2007060634, indexed in Pubmed: 18235095.

26. Navarro-Muñoz M, Bonet J, Bayés B, et al. Atorvastatin treatment in the short term: does it induce renoprotection or vasculoprotection in renal transplantation? Transplant Proc. 2007; 39(7): 2259-2263, doi: 10.1016/j.transproceed.2007.06.007, indexed in Pubmed: 17889157. 